\title{
Folate bio-fortification of yoghurt and fermented milk: a review
}

\author{
Aziz Homayouni Rad ${ }^{1} \cdot$ Ahmad Yari Khosroushahi ${ }^{2}$. \\ Mohammad Khalili $^{3} \cdot$ Somayeh Jafarzadeh $^{1}$
}

Received: 5 December 2015 / Revised: 7 March 2016 / Accepted: 8 March 2016 /

Published online: 23 March 2016

(C) INRA and Springer-Verlag France 2016

\begin{abstract}
Folate, an essential vitamin, plays an important role in human life for the synthesis of nucleotides, vitamins and some amino acid. This vitamin cannot be synthesized by humans and must be obtained exogenously to prevent folate deficiency, neural tube defects (NTDs) and other related diseases. Folic acid, the chemically synthesized form of folate, is used for fortification and supplementation, but it can cause adverse effects such as vitamin $B_{12}$ deficiency in high intake. Therefore, novel methods to increase concentrations of naturally occurring folate in foods have grabbed the interest of researchers. The application of bacterial cultures in food fermentation is a novel strategy to increase "natural" folate levels. Dairy products, especially yoghurt, are an appropriate choice for bio-fortification of folate as they contain folate-binding protein which improves folate bioavailability. This study will review the folate production by probiotic bacteria in fermented milk based on various strains and culture conditions.
\end{abstract}

Keywords Probiotic $\cdot$ Folate $\cdot$ Folic acid $\cdot$ Bio-fortification $\cdot$ Yoghurt

\section{Introduction}

Folate belongs to the water-soluble B-group of vitamins. It is also referred to as vitamin $\mathrm{B}_{9}$, vitamin $\mathrm{B}_{\mathrm{c}}$ (or folacin), and pteroyl-L-glutamate. This vitamin is found in a wide variety of foods. However, folate deficiencies are a very frequent phenomenon in many

Somayeh Jafarzadeh

somaye.jafarzade@yahoo.com

1 Department of Food Science and Technology, Faculty of Nutrition, Tabriz University of Medical Sciences, Tabriz, Iran

2 Department of Pharmacognosy, Faculty of Pharmacy, Tabriz University of Medical Sciences, Tabriz, Iran

3 Neurosciences Research Center, Tabriz University of Medical Sciences, Tabriz, Iran 
countries. There is an increased risk of vitamin deficiency in some population groups, especially in the elderly, because their food intake is lower, in children, who sometimes consume a limited variety of foods, and for pregnant women because of the critical role played by folate in foetus neural tube development. Low folate intake increases the risk of birth defects in newborn babies.

Probiotic bacteria confer beneficial effects to their hosts and are known for the production of folate in high amounts (Hugenschmidt et al. 2010, 2011; Iyer et al. 2010; LeBlanc et al. 2007).

Different types of products have been proposed as carrier foods for probiotic microorganisms by which consumers can take in large amounts of probiotic cells for therapeutic effects. Yoghurt has long been recognized as a product with many desirable effects for consumers, and it is also important that most consumers consider yoghurt to be healthy.

Strains exhibiting high vitamin production capacities have high application potential for enriching fermented products with natural vitamins (Lourens-Hattingh and Viljoen 2001).

This study follows a brief presentation of folate in terms of chemistry, nutritional aspects, biosynthesis, bioavailability and analysis. After that, fermented dairy products with emphasis on yoghurt are reviewed for their folate content. Special emphasis is placed on the probiotic strains that have significant capacity to produce folate in different fermented milks with various culture conditions.

\section{Folate}

\subsection{Chemical structure of folate}

The term "folate" refers to all groups of folic acid derivatives, containing the natural folate form present in foods and synthetic folic acid form used for food fortification and vitamin supplements. Folic acid (pteroyl-L-glutamic acid; Fig 1a) (PGA) is composed of para-aminobenzoic acid (pABA), pteridine ring and L-glutamic acid (Fig. 1a). The natural folate forms exist primarily as reduced, with different reduction levels of the pteroyl group, the number of substituents and that of glutamyl residues attached to the pteroyl group (Fig. 1b).

The various folate derivatives include 5-methyltetrahydrofolate (5-MTHF), 5formyltetrahydrofolate (5-formyl-THF), 10-formyltetrahydrofolate (10-formyl-THF), 5,10-methylenetetrahydrofolate (5,10-methylene-THF), 5,10-methenyltetrahydrofolate (5,10-methenyl-THF), 5-formiminotetrahydrofolate (5-formimino-THF), 5,6,7,8tetrahydrofolate (THF) and dihydrofolate (DHF). Over 100 distinct forms of this vitamin may exist naturally as a result of this chemical diversity, although fewer than 50 principal forms of folate exist in most animal and plant tissues (Gregory 1989).

Most naturally occurring dietary folates have two to seven glutamate units attached on peptide linkages. The intracellular folates are mostly pteroylpentaglutamates, while the pteroylmonoglutamates are dominant forms of extracellular folate. Naturally, pteroylpolyglutamates with a maximum of 11 glutamic acid residues exist (Forssén et al. 2000; Holasova et al. 2005; LeBlanc et al. 2007; Sybesma et al. 2003; Sybesma 2003). 
a<smiles>Nc1nc(O)c2nc(C=Nc3ccc(C(=O)NC(CCC(=O)O)C(=O)O)cc3)cnc2n1</smiles>

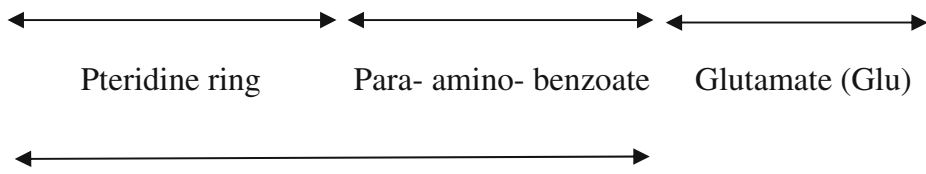

Pteroate (Pte)

Para- aminobenzoylglutamic acid (PABG)

Pteroyl glutamic acid (PGA)(Folic acid)

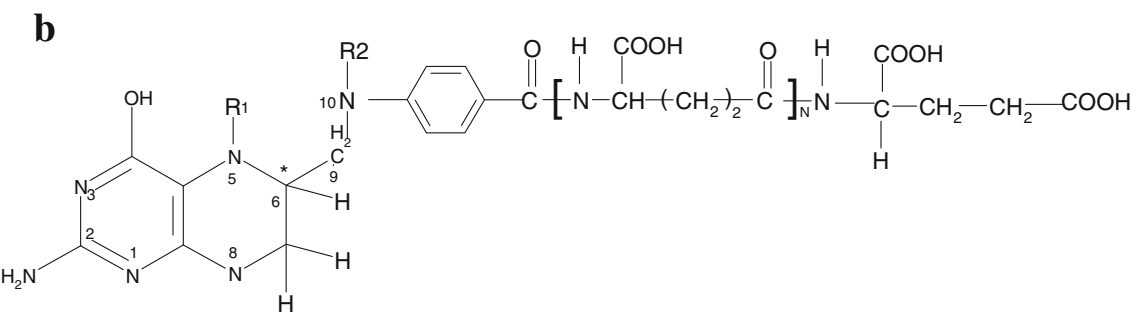

Tetrahydropteroylpolyglutamates

\begin{tabular}{|l|l|l|}
\hline $\mathrm{R} 1$ & $\mathrm{R} 2$ & Folate derivative \\
\hline$-\mathrm{H}$ & $-\mathrm{H}$ & Tetrahydrofolate (THF) \\
\hline$-\mathrm{CH}_{3}$ & $-\mathrm{H}$ & 5 -methyltetrahydrofolate (5-methyl- THF) \\
\hline$-\mathrm{CH}=\mathrm{NH}$ & $-\mathrm{H}$ & 5 -formiminotetrahydrofolate (5-formimino-THF) \\
\hline$-\mathrm{HCO}$ & $-\mathrm{H}$ & 5 -formyltetrahydrofolate (5-formyl-THF) \\
\hline$-\mathrm{H}$ & $-\mathrm{HCO}$ & 10-formyltetrahydrofolate (10-formyl-THF) \\
\hline \multicolumn{2}{|c|}{ Bridge $\mathrm{R} 1-\mathrm{R} 2$} & \\
\hline \multicolumn{2}{|c|}{$-\mathrm{CH}_{2}^{-}$} & 5,10 -methylentetrahydrofolate (5,10-methylen-THF) \\
\hline \multicolumn{2}{|c|}{$-\mathrm{CH}^{-}=$} & 5,10 -methenyltetrahydrofolate (5,10-methenyl-THF) \\
\hline
\end{tabular}

Fig. 1 Structure and name of some folate derivatives with fully oxidized (folic acid) (a) and fully reduced pteridine ring (natural folate) (b). $N$ The number of extra glutamate units 


\subsection{Nutritional and health aspects}

Folate is not synthesized in mammalian cells; hence, it must be supplied exogenously. This vitamin plays important roles in various metabolic pathways, acting as cofactor for one carbon transferring reactions in methylation cycle, DNA replication as well as biosynthesis of nucleic acids, some amino acids and vitamins (Hanson and Roje 2001; Laiño et al. 2013). In addition to the mentioned functions, folate has an antioxidant property which protects the genome against free radical damage (Duthie et al. 2002; LeBlanc et al. 2007).

The approved daily recommended intake of folate in the European Union is $400 \mu$ g.day $^{-1}$ for adults (FAO and WHO 2005). Except pregnant and lactating women, the minimum folate requirement for adults has been estimated at $50 \mu \mathrm{g}^{\mathrm{day}}{ }^{-1}$ (Crittenden et al. 2003). In addition, dietary intake of 400-600 $\mu \mathrm{g}^{\mathrm{day}}{ }^{-1}$ is commonly recommended for pregnant women (Allen 2003; Brachet et al. 2004; Crittenden et al. 2003; Laiño et al. 2013).

Folate is mainly found in yeast, liver, wheat bran, beetroot, green leafy vegetables, chick peas, nuts, legumes, citrus and some fruits. Other sources include oatmeal, whole grain cereals, potatoes, eggs, kidney, muscle meats, fish and fermented dairy products (Eitenmiller et al. 2007; Holasova et al. 2005; LeBlanc et al. 2007). It has been stated that a food is considered a good source of folate when it contributes to at least $10-20 \%$ of daily recommended intake (FAO and WHO 2005).

Despite the wide range of dietary sources for folate, folate deficiencies still occur frequently. Such deficiency has been reported in a wide variety of disorders. A noteworthy disease related to folate deficiency is neural tube defect (NTD) (Geisel 2003; Storozhenko et al. 2005). Homocysteine, a metabolite of folate deficiency, is raised in blood samples and is called homocysteinuria. Hyper homocysteinuria is a predictor of cardiovascular disease and a risk factor for dementia and Alzheimer's disease (LeBlanc et al. 2007; Luchsinger et al. 2007; Storozhenko et al. 2005). In addition, coronary heart disease, osteoporosis, breast and colorectal cancer (Rossi et al. 2011), pancreatic, cervical cancer and leukaemia (Díaz de la Garza et al. 2007; Storozhenko et al. 2005), and hearing loss (Laiño et al. 2012) are related to folate deficiency.

Insufficient folate intakes have been reported among various population groups such as pregnancy-age women in many parts of the world, including developing countries, and some industrialized countries (LeBlanc et al. 2007; Morris and Tangney 2007). The high prevalence of NTD, a result of folate deficiency in pregnant women, obligates the governing bodies of many countries to fortify foods with folic acid. On the other hand, the potential side effects of folic acid fortification are a reason for not adopting folic acid fortification in some countries (Sherwood et al. 2006). For example, over consumption of folic acid (more than $1 \mathrm{mg}$ /day) is not toxic but may cover the appearance of vitamin $B_{12}$ deficiency (Ray et al. 2003; Storozhenko et al. 2005). The other adverse effects of high intake of chemically synthesized form of folate include change in activity of the hepatic dihydrofolatereductase enzyme (Bailey and Ayling 2009) or promotion of cancer (Baggott et al. 2012; Laiño et al. 2013; Ulrich and Potter 2006). Recently, it has been reported that foetus exposure to excess folic acid results in methylenetetrahydrofolate polymorphism associated with a range of debilitating illnesses (Sweeney et al. 2007). In contrast, natural folate found in foods and produced by 
microorganisms does not have the mentioned adverse health effects (Laiño et al. 2013; Wright et al. 2007).

\subsection{Biosynthesis and metabolism}

Biosynthesis of folate pathway in microorganisms is composed of several parts. The three main structural parts of folate are pteridine, para-aminobenzoic acid (pABA) and glutamate. The pteridine moiety of folate is made from guanosine triphosphate (GTP), which is synthesized in purine biosynthesis pathway (Fig. 2). The reaction of GTP to dihydroneopterin is catalyzed by GTP cyclohydrolase. Then phosphatase removes a phosphate residue. After that, dihydroneopterin aldolase acts on the product to give glycolaldehyde and 6-hydroxymethyl-7,8-dihydropterin, which is converted to 6hydroxymethyl-7,8-dihydropterin pyrophosphate (DHPPP) by 6-hydroxymethyldihydropteridine pyrophosphokinase. Dihydropteroate synthase pairs DHPPP to para-aminobenzoic acid. pABA originates from chorismate in the same pathways involved in aromatic amino acid, glycolysis, pentose phosphate pathway and shikimate pathway. The joining of C-N bound of DHPPP to pABA forms dihydropteroate (DHP). DHP is glutamylated with glutamate taken up from the medium and is then reduced by DHF reductase to the biologically active cofactor tetrahydrofolate (THF). Finally, multiple glutamate moieties are added by polyglutamate folate synthetase to yield THF-polyglutamate (Rossi et al. 2011; Sybesma 2003).

The metabolism of folate happens in several enzymatic pathways; the reductase enzyme reduces the pterin ring in kidney and liver, reaction of polyglutamyl side chain by polyglutamatesynthetase, and adding one-carbon units to certain positions of the pterin ring. The metabolically active forms of folate include 5-methyl-THF, 5-formylTHF, 10-formyl-THF, 5,10-methylene-THF, 5,10-methenyl-THF and 5-formiminoTHF (Mahan et al. 2012).

\subsection{Bioavailability}

Bioavailability is defined as a fraction of ingested nutrient which is available for metabolic process or storage in the body. While folate is found in foods as monoglutamate and polyglutamate, the polyglutamate form has $60-80 \%$ bioavailability compared to monoglutamate. Therefore, the attachment of polyglutamate chain to folate may decrease bioavailability of folate (LeBlanc et al. 2007). However, the $\gamma$ glutamyl hydrolase or human conjugase in brush border of the small intestine removes the polyglutamate chain, after which the monoglutamate form can be absorbed (MelseBoonstra et al. 2004; Sybesma 2003). Compared to synthetic folic acid, naturally occurring dietary folate is only $80 \%$ bioavailable (Mahan et al. 2012). The folatebinding protein in milk may increase folate absorption by protecting dietary folate uptake by gut bacteria (Eitenmiller et al. 2007; Forssén et al. 2000; LeBlanc et al. 2007). Furthermore, dietary factors such as alcoholism, chelation and certain drugs may affect intestinal $\mathrm{pH}$ and thus folate absorption (LeBlanc et al. 2007). The nutritional status of folate depends on intake from food and supplements with various bioavailabilities. Therefore, the level of folate bioavailability as well as the level of folate polyglutamylation determines the effective intake of folate (Clifford et al. 1991; 


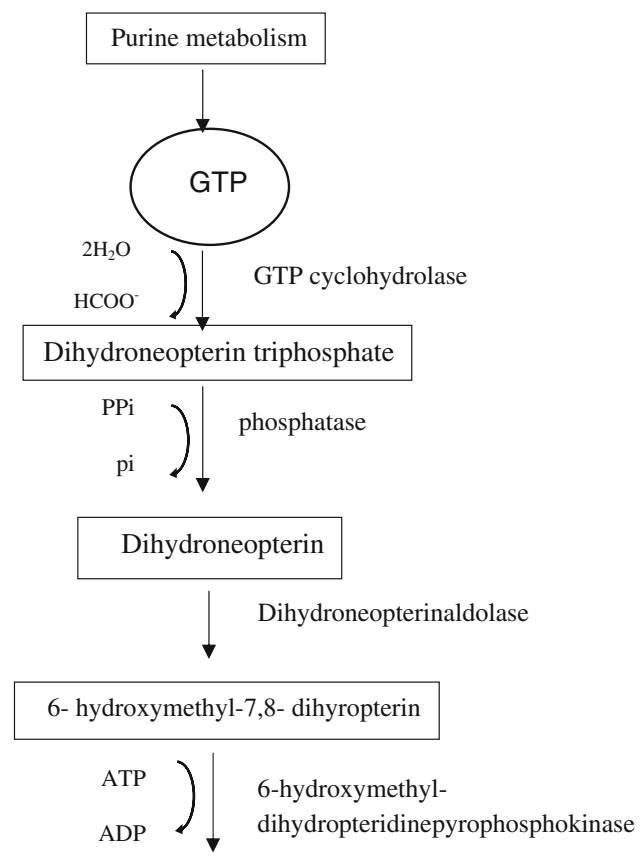

6- hydroxymethyl-7,8- dihyropterin pyrophosphate

(DHPPP)

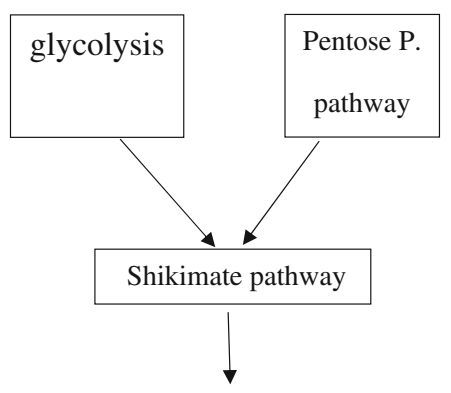

Chorismate

Amino

$\checkmark$ deoxychorismate synthase

4- amino- 4-

deoxychorismate

Para-Aminobenzoate

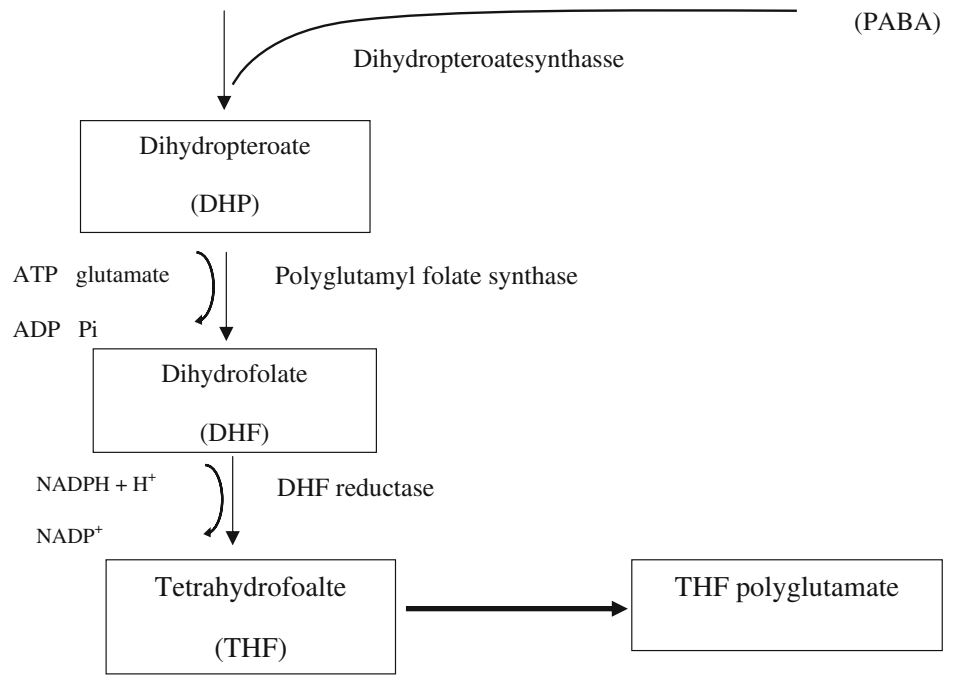

(PABA)

Polyglutamyl folate synthase

Fig. 2 Pathway of folate biosynthesis in lactic acid bacteria (LAB). GTP guanosine triphosphate

Gregory III 1989; Melse-Boonstra et al. 2004; Sybesma 2003). It is believed that predominant natural conjugase inhibitors such as anionic species of organic acids (citrate, malate and ascorbate) in food inhibit the action of conjugase and decrease efficient folate uptake in the gastrointestinal tract leading to a decline in folate 
bioavailability as opposed to the chemically synthesized folic acid in supplements and fortified foods (Gregory 2001; Sybesma 2003).

\subsection{Folate analysis methods}

Folate is sensitive to light, oxidation, heat and acids, so an analytical method with high sensitivity is needed. Some analytical techniques used for the determination of folate content are biological, such as microbiological and competitive protein-binding procedures. In spite of sensitivity, these methods lack the specificity to separate different folate forms. Other methods are chemical ones, such as high-performance liquid chromatography (HPLC) method (LeBlanc et al. 2007; Storozhenko et al. 2005; Vahteristo and Finglas 2000).

In the competitive protein-binding assay, folate content is determined through developed colour measurement in microtitration plate which results from competition between sample folate and radio-labelled folate for attaching to folatebinding protein. Despite the speed and convenience of this assay, this method has varied affinity for different forms of folate and is suitable only for foods with the same form of folate. It is less useful for analyzing foods with several types of folate forms and more complex matrices (Arcot and Shrestha 2005; LeBlanc et al. 2007).

As the traditional method of folate analysis, microbiological assay is based on the nutritional requirements of microorganisms, especially Lactobacillus rhamnosus (Horne and Patterson 1988), and is used for the analysis of total folate in foods and responds to most native folate. In this assay, the growth of microorganisms is dependent on the amount of folate in the medium; therefore, the rate of microorganism growth is measured by change in solution turbidity, presents the amount of folate. The microbiological method has been considered to be one of the most versatile methods for determining food folate, but it has some limitations such as providing inadequate information on the forms of folate, as well as the fact that it needs experts, and it can also be a tedious procedure (Arcot and Shrestha 2005).

The HPLC method, which separates and detects the different forms based on their chemical structure, is more interesting. The advantages of HPLC are high specificity and reliability, and minimal interference from food enzymes. In the HPLC method, one needs to use all known forms of folate to quantify total folate. Some of them are hard and expensive to detect, which constitutes a potential major limitation. In addition, HPLC is not able to separate folates based on their structure and size at the same time (Arcot and Shrestha 2005; LeBlanc et al. 2007; Lin and Young 2000). However, HPLC has been used to measure folate in several foods including dairy products (Gregory 3rd et al. 1984; Holt et al. 1988).

The known analytical methods to be used for a particular biological material depend on the sample matrix and purpose of the assay. Basically, three main parts of folate analysis in plants and foods include extraction, deconjugation and detection/quantification. Depending on the sample matrix and on the chemical structure of the target compounds, the extraction process can vary considerably. The sample preparation and extraction methods largely affect the amount of extracted folate content, which is then evaluated by a chosen method (Arcot and Shrestha 2005; Vahteristo and Finglas 2000). 


\section{Natural synthesis of folate by probiotic lactic and propionic acid bacteria}

The consumption of live microorganisms called probiotics that provide health benefits for human physiology has become a common practice. According to the common definition accepted by $\mathrm{FAO} / \mathrm{WHO}$, probiotics are defined as live microbes which, when administered in adequate amounts, confer a health benefit on the host (FAO/WHO 2006). For a strain to be determined as probiotic, it should preferably be of human origin, have a status generally recognized as safe (GRAS), be able to survive through the gastrointestinal tract, adhere to the human intestinal cells, be antagonistic towards potential pathogenic microorganisms and have several health benefit effects on the host (Collins et al. 1998; Iyer et al. 2010). Probiotic bacteria have a positive effect on the immune system and intestinal microbiotic composition and functions and have been claimed to be therapeutic or preventive against infections and several autoimmune and atopic diseases (Collins et al. 1998; Homayouni Rad et al. 2013a, 2013b; Rossi et al. 2011; Schrezenmeir and de Vrese 2001; Singh et al. 2011).

Probiotic microorganisms have been recognized within different bacteria and yeast phylum. Besides Lactobacillus and Bifidobacterium, species belonging to the genera Lactococcus, Enterococcus, Streptococcus and Propionibacterium are currently known to be probiotic microorganisms, conferring a number of health benefits such as vitamin production (Rad AH et al. 2012; Iyer et al. 2010; Rossi et al. 2011; Sanders and Huis 1999).

Recent reports have shown that some probiotic microorganisms have the potential ability to synthesize folate (Table 1). It is reported by Sybesma et al. that Lactococcus lactis has a great potential to produce high amounts of folate (Sybesma et al. 2003; Sybesma 2003). Other researchers have also reported that many strains of Bifidobacterium were able to produce folate. Several folate-producing Bifidobacterium strains have been investigated, but the produced folate does not seem to be widespread within the genus strains of Bifidobacterium bifidum, Bifidobacterium infantis, Bifidobacterium breve, Bifidobacterium longum, and Bifidobacterium adolescentis cultured in a folate-free semisynthetic medium. Most of bifidobacteria belonging to the species B. adolescentis and Bifidobacterium pseudocatenulatum have a high potential to produce folate, but other strains produce less folate (Pompei et al. 2007; Rossi et al. 2011). In another study, B. longum strains cultured in reconstitute skim milk (RSM) had higher levels of folate than other tested species as shown in Table 1 (Lin and Young 2000).

Among the Lactobacillus species, only Lactobacillus plantarum can produce folate, whereas other species were shown to consume folate during growth (Sybesma et al. 2003). However, several studies have reported that different kinds of Lactobacillus can be included on the list of folate-producing bacteria (Hugenschmidt et al. 2010). These properties depend on many factors such as the strain of bacteria, culturing media, incubation time and others (Crittenden et al. 2003; Laiño et al. 2012; Lin and Young 2000; Nor et al. 2010; Sybesma et al. 2003). Propionibacteria, other probiotic bacteria, have been demonstrated as folate-producing bacteria, able to produce vitamin $\mathrm{B}_{12}$ and stimulate growth of $L$. plantarum. Their other properties include inhibition of undesirable microflora in fermented foods via releasing of organic acids and bacteriocins. They were shown to modulate the colon flora both in animals and humans beneficially, by enhancing the indigenous bifidobacteria population (Bougle et al. 1999; Chaia et al. 1999; Hugenholtz et al. 2002). Hugenschmidt et al. showed that optimized culture 


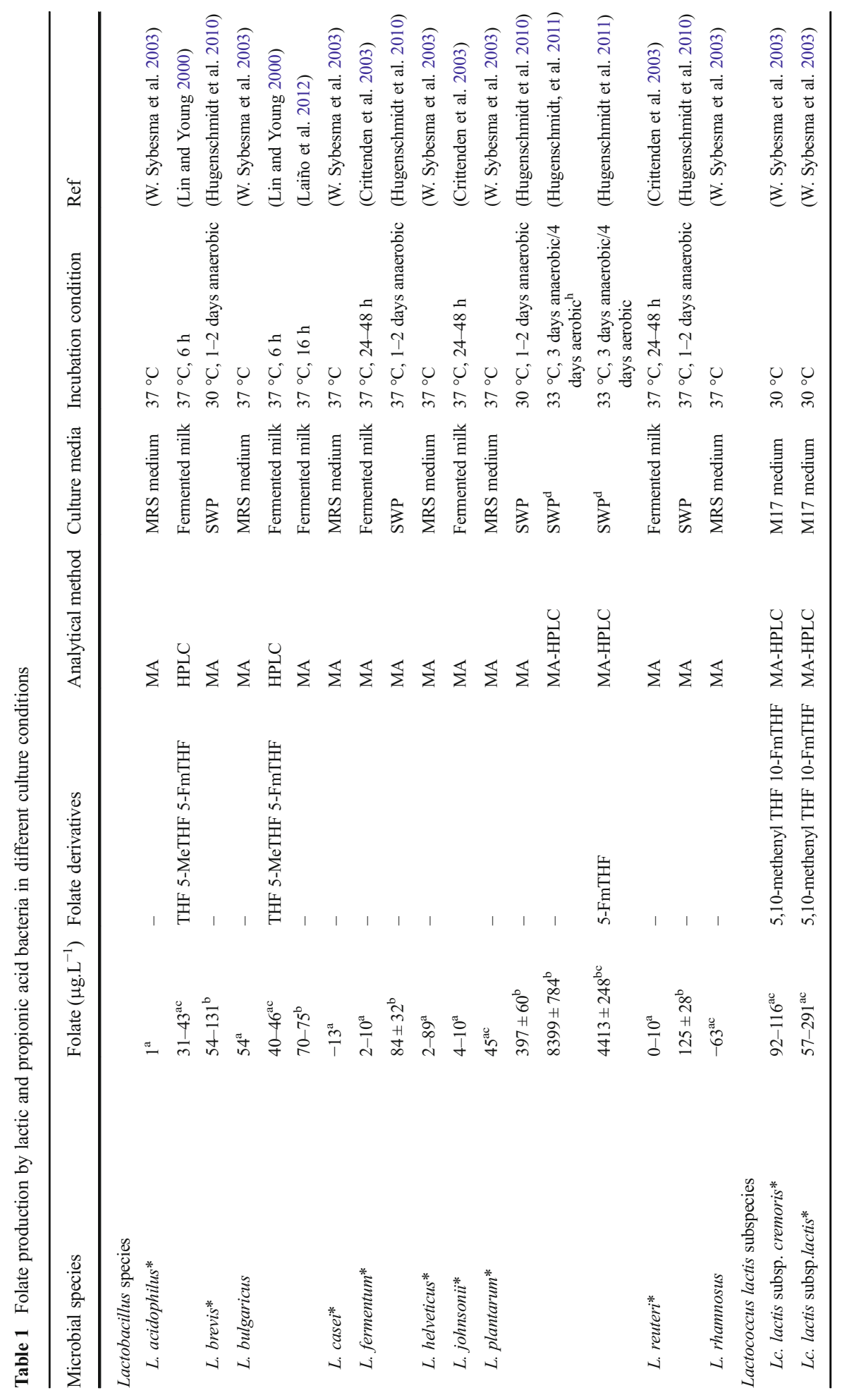




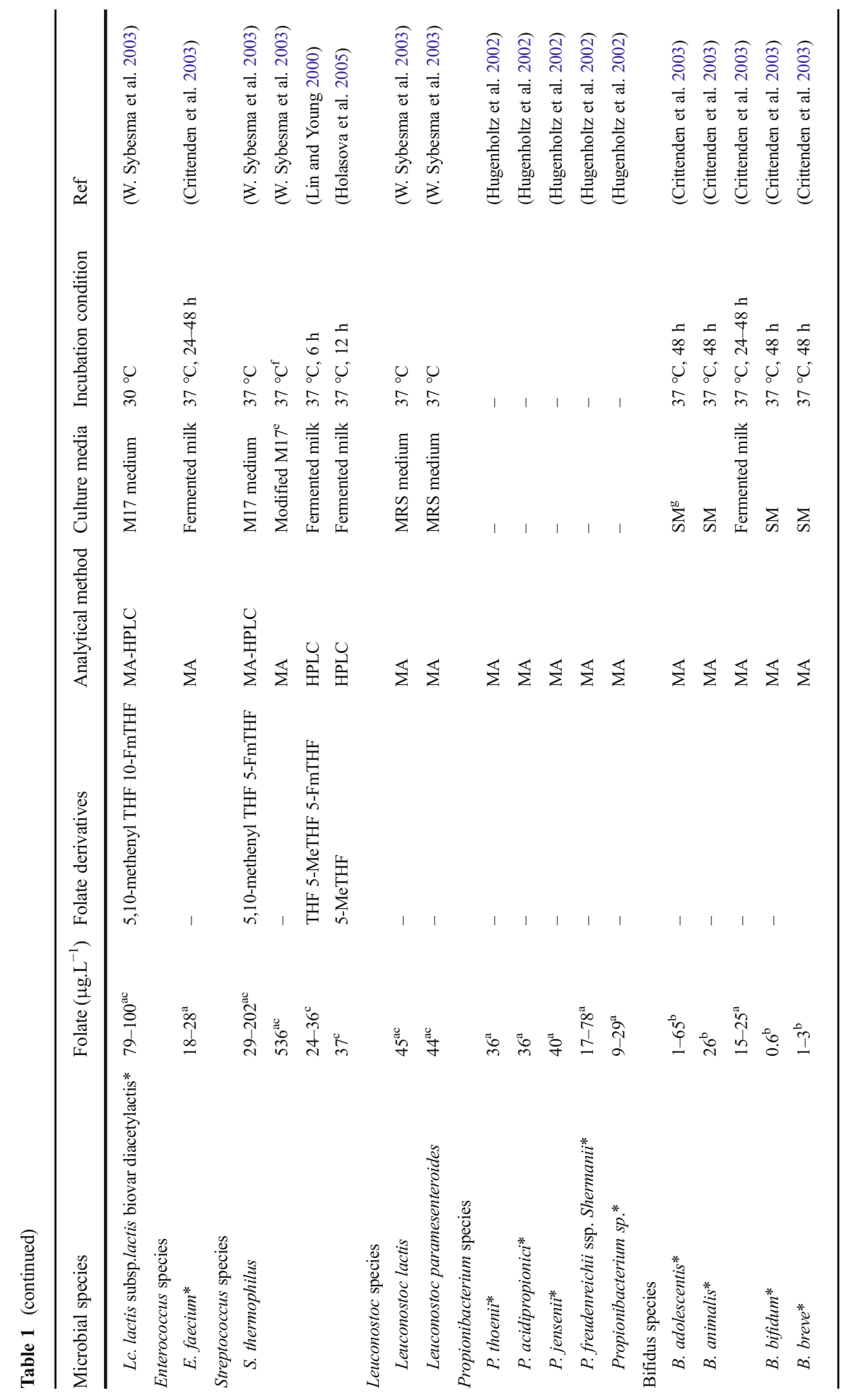

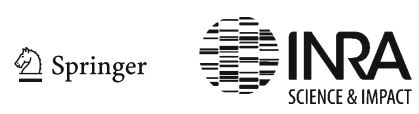




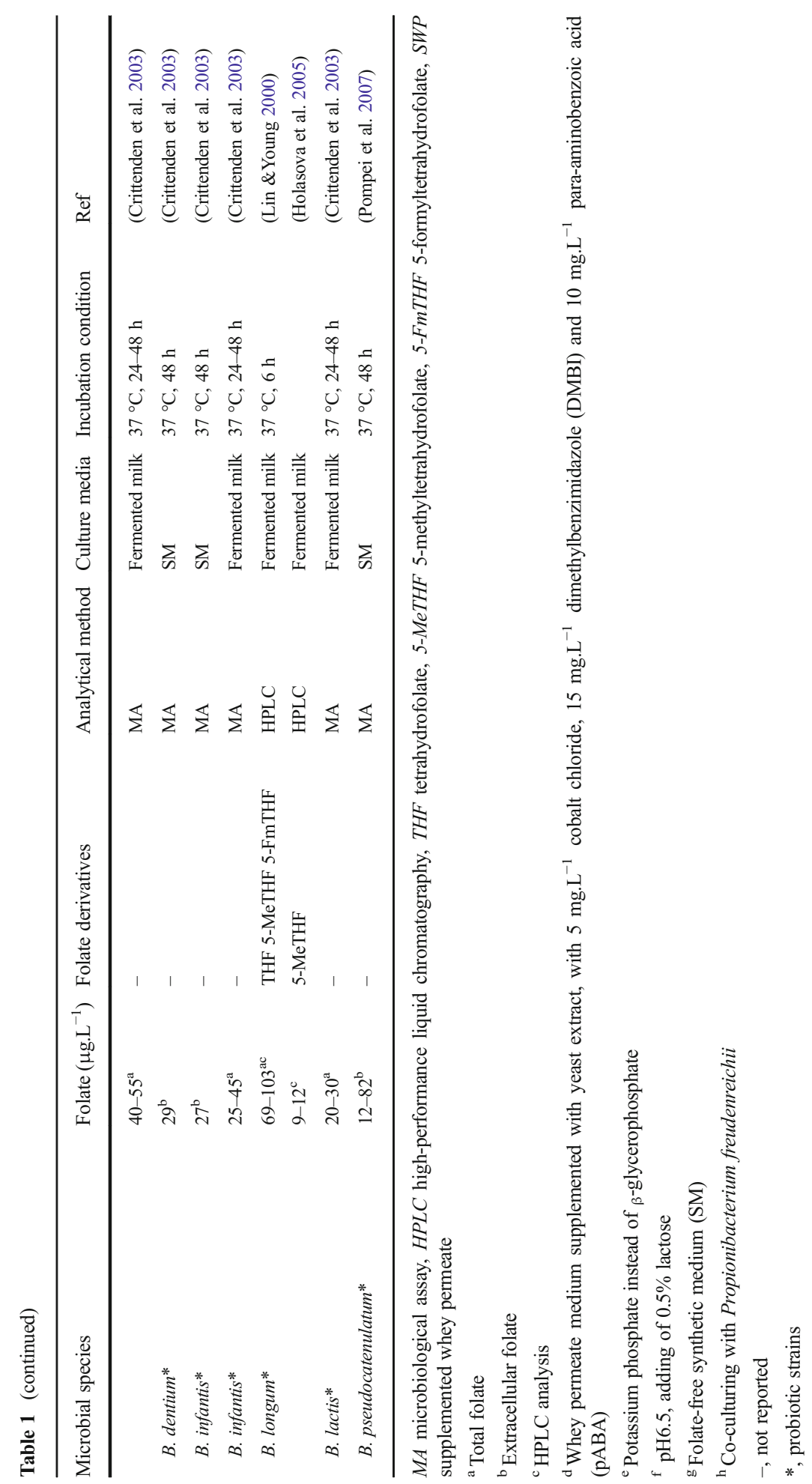


media accompanied with Propionibacterium freudenreichii stimulated L. plantarum and led to ten times higher increases in folate levels than maximum values reported for natural fermentations (Hugenschmidt et al. 2011).

\section{Folate production in milk and yoghurt}

Milk is not a rich source of dietary folate, but fermented dairy products such as yoghurt processed by starter culture are regarded as important dietary sources of folate (Kneifel et al. 1989; LeBlanc et al. 2007). The ability of yoghurt starter cultures (Lactobacillus bulgaricus and Streptococcus thermophilus) to produce folate is very variable and depends on strains (Alm 1982; Crittenden et al. 2003; Kneifel et al. 1989, 1992; Laiño et al. 2013). It is reported that L. bulgaricus are folate consumers (Kneifel et al. 1991; Laiño et al. 2012, 2013; Rao et al. 1984). However, certain strains of L. bulgaricus are able to produce folate when grown in a folate-free medium and in milk (Laiño et al. 2012, 2013). Against various data regarding the synthesis of this vitamin by Lactobacillus species, it was demonstrated that L. plantarum has the ability to produce high levels of folate, when grown in an optimized medium, as shown in Table 1 (Hugenschmidt et al. 2011). Most previous and recent studies based on HPLC method have indicated that 5-methyl-tetrahydrofolate (5-methyl-THF) is the major form of folate in milk and yoghurt. Based on the three main folate analysis methods, HPLC, radio protein binding and microbiological assays, the same ranges of folate have been detected in cow's milk (50-100 $\left.\mu \mathrm{g} . \mathrm{L}^{-1}\right)$, while its concentration may be increased to more than $200 \mu \mathrm{g} . \mathrm{L}^{-1}$ depending on applied starter cultures and storage conditions (Hugenschmidt et al. 2011; Laiño et al. 2014).

In this line, optimal combination of $S$. thermophilus and L. bulgaricus strains results in organoleptically desirable yoghurt with increased folate levels. Therefore, using different starters may be an explanation for folate content and variations in its form (Forssén et al. 2000; Holasova et al. 2005).

It is reported that the use of folate-producing probiotic bacteria in combination with $S$. thermophilus and/or L. bulgaricus provides the largest increase in folate during the fermentation process of probiotic yoghurt compared to original milk and conventional fermented milk (Crittenden et al. 2003; Jägerstad et al. 2005; Rossi et al. 2011).

\section{Conclusions}

This review has concluded that bio-fortification of folate in yoghurts and fermented milks is possible through proper selection of the microbial strains of probiotics and cultivation conditions. It is believed that bio-fortified fermented milks containing elevated levels of natural folate with improved stability and bioavailability would be a good source of folate. Based on the fact that traditional or commercial yoghurts cannot meet at least $10-20 \%$ of daily recommended intake as well as there are no commercial yoghurts or any other fermented dairy products naturally fortified with folate, there is an opportunity for food industry settings to take the next step and use this information for selecting folate-producing strains as part of their starter cultures in order to produce fermented products with elevated levels of this essential vitamin. This 
attempt is a cost-effective move by food manufacturers since increased "natural" folate concentrations would be an important value-added effect without increasing production costs. The proper selection of probiotic folate-producing strains provides a strategy for the development of novel and functional foods with increased nutritional values.

\section{References}

Allen LH (2003) B vitamins: proposed fortification levels for complementary foods for young children. J Nutr 133:3000S-3007S

Alm L (1982) Effect of fermentation on B-vitamin content of milk in Sweden. J Dairy Sci 65:353-359

Arcot J, Shrestha A (2005) Folate: methods of analysis. Trends Food Sci Technol 16:253-266

Baggott JE, Oster RA, Tamura T (2012) Meta-analysis of cancer risk in folic acid supplementation trials. Cancer Epidemiol 36:78-81

Bailey SW, Ayling JE (2009) The extremely slow and variable activity of dihydrofolate reductase in human liver and its implications for high folic acid intake. Proc Natl Acad Sci 106:15424-15429

Bougle D, Roland N, Lebeurrier F, Arhan P (1999) Effect of propionibacteria supplementation on fecal bifidobacteria and segmental colonic transit time in healthy human subjects. Scand J Gastroenterol 34: 144-148

Brachet P, Chanson A, Demigné C, Batifoulier F, Alexandre-Gouabau M-C, Tyssandier V, Rock E (2004) Age-associated B vitamin deficiency as a determinant of chronic diseases. Nutr Res Rev 17:55-68

Chaia AP, Zarate G, Oliver G (1999) The probiotic properties of propionibacteria. Lait 79:175-185

Clifford A, Heid M, Peerson J, Bills N (1991) Bioavailability of food folates and evaluation of food matrix effects with a rat bioassay. J Nutr 121:445-453

Collins J, Thornton G, Sullivan G (1998) Selection of probiotic strains for human applications. Int Dairy J 8:487-490

Crittenden R, Martinez N, Playne M (2003) Synthesis and utilisation of folate by yoghurt starter cultures and probiotic bacteria International Journal of Food Microbiology 80:217-222

Díaz de la Garza RI, Gregory JF, Hanson AD (2007) Folate biofortification of tomato fruit. Proc Natl Acad Sci U S A 104:4218-4222

Duthie SJ, Narayanan S, Brand GM, Pirie L, Grant G (2002) Impact of folate deficiency on DNA stability. J Nutr 132:2444S-2449S

Eitenmiller RR, Landen Jr W, Ye L (2007) Vitamin analysis for the health and food sciences. CRC press

FAO, WHO (2005) Vitamin and mineral requirements in human nutrition

FAO/WHO (2006) Probiotics in food: health and nutritional properties and guidelines for evaluation. Food and Agriculture Organization of the United Nations

Forssén KM, Jägerstad MI, Wigertz K, Witthöft CM (2000) Folates and dairy products: a critical update. J Am Coll Nutr 19:100S-110S

Geisel J (2003) Folic acid and neural tube defects in pregnancy: a review. J Perinat Neonatal Nurs 17:268-279

Gregory JF III (1989) Chemical and nutritional aspects of folate research: analytical procedures, methods of folate synthesis, stability, and bioavailability of dietary folates. Adv Food Nutr Res 33:1-101

Gregory JF (2001) Case study: folate bioavailability. J Nutr 131:1376S-1382S

Gregory J 3rd, Sartain DB, Day B (1984) Fluorometric determination of folacin in biological materials using high performance liquid chromatography. J Nutr 114:341-353

Hanson AD, Roje S (2001) One-carbon metabolism in higher plants. Annu Rev Plant Biology 52:119-137

Holasova M, Fiedlerova V, Roubal P, Pechacova PM (2005) Possibility of increasing natural folate content in fermented milk products by fermentation and fruit component addition. Czech J Food Sci 23:196-201

Holt DL, Wehling RL, Zeece MG (1988) Determination of native folates in milk and other dairy products by high-performance liquid chromatography. J Chromatogr A 449:271-279

Homayouni Rad A, Torab R, Ghalibaf M, Norouzi S, Mehrabany EV (2013a) Might patients with immunerelated diseases benefit from probiotics? Nutrition 29:583-586

Homayouni Rad A, Torab R, Mortazavian AM, Mehrabany EV, Mehrabany LV (2013b) Can probiotics prevent or improve common cold and influenza? Nutrition 29:805-806

Horne DW, Patterson D (1988) Lactobacillus casei microbiological assay of folic acid derivatives in 96-well microtiter plates. Clin Chem 34:2357-2359

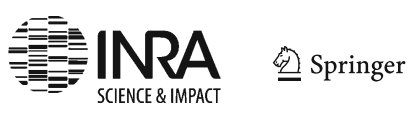


Hugenholtz J, Hunik J, Santos H, Smid E (2002) Nutraceutical production by propionibacteria. Lait $82: 103-112$

Hugenschmidt S, Schwenninger SM, Gnehm N, Lacroix C (2010) Screening of a natural biodiversity of lactic and propionic acid bacteria for folate and vitamin B12 production in supplemented whey permeate. Int Dairy J 20:852-857. doi:10.1016/j.idairyj.2010.05.005

Hugenschmidt S, Schwenninger SM, Lacroix C (2011) Concurrent high production of natural folate and vitamin B12 using a co-culture process with Lactobacillus plantarum SM39 and Propionibacterium freudenreichii DF13. Process Biochem 46:1063-1070. doi:10.1016/j.procbio.2011.01.021

Iyer R, Tomar S, Kapila S, Mani J, Singh R (2010) Probiotic properties of folate producing Streptococcus thermophilus strains. Food Res Int 43:103-110

Jägerstad M, Piironen V, Walker C, Ros G, Carnovale E, Nau H, Holasova M (2005) Increasing natural food folates through bioprocessing and biotechnology. Trends Food Sci Technol 16:298-306

Kneifel W, Holub S, Wirthmann M (1989) Monitoring of B-complex vitamins in yogurt during fermentation. J Dairy Res 56:651-656

Kneifel W, Erhard F, Jaros D (1991) Production and utilization of some water-soluble vitamins by yogurt and yogurt-related starter cultures. Milchwissenschaft 46:685-690

Kneifel W, Kaufmann M, Fleischer A, Ulberth F (1992) Screening of commercially available mesophilic dairy starter cultures: biochemical, sensory, and microbiological properties. J Dairy Sci 75:3158-3166

Laiño JE, LeBlanc JG, Savoy de Giori G (2012) Production of natural folates by lactic acid bacteria starter cultures isolated from artisanal Argentinean yogurts. Can J Microbiol 58:581-588

Laiño JE, Juarez del Valle M, Savoy de Giori G, LeBlanc JGJ (2013) Development of a high folate concentration yogurt naturally bio-enriched using selected lactic acid bacteria. LWT Food Sci Technol 54:1-5. doi:10.1016/j.lwt.2013.05.035

Laiño JE, del Valle MJ, de Giori GS, LeBlanc JGJ (2014) Applicability of a Lactobacillus amylovorus strain as co-culture for natural folate bio-enrichment of fermented milk International journal of food microbiology 191:10-16

LeBlanc JG, de Giori GS, Smid EJ, Hugenholtz J, Sesma F (2007) Folate production by lactic acid bacteria and other food-grade microorganisms Communicating current research and educational topics and trends in applied microbiology 1:329-339

Lin MY, Young CM (2000) Folate levels in cultures of lactic acid bacteria. Int Dairy J 10:409-413. doi:10. 1016/S0958-6946(00)00056-X

Lourens-Hattingh A, Viljoen BC (2001) Yogurt as probiotic carrier food. Int Dairy J 11:1-17

Luchsinger JA, Tang M-X, Miller J, Green R, Mayeux R (2007) Relation of higher folate intake to lower risk of Alzheimer disease in the elderly. Arch Neurol 64:86-92

Mahan LK, Escott-Stump S, Raymond JL (2012) Krause's food \& the nutrition care process. 13 edn. Elsevier Health Sciences

Melse-Boonstra A, West CE, Katan MB, Kok FJ, Verhoef P (2004) Bioavailability of heptaglutamyl relative to monoglutamyl folic acid in healthy adults. Am J Clin Nutr 79:424 429

Morris MC, Tangney CC (2007) Is dietary intake of folate too low? Lancet 369:166

Nor NM, Mohamad R, Foo HL, Rahim RA (2010) Improvement of folate biosynthesis by lactic acid bacteria using response surface methodology. Food Technol Biotechnol 48:243-250

Pompei A, Cordisco L, Amaretti A, Zanoni S, Matteuzzi D, Rossi M (2007) Folate production by bifidobacteria as a potential probiotic property. Appl Environ Microbiol 73:179-185

Rad AH, Mehrabany EV, Alipoor B, Mehrabany LV, Javadi M (2012) Do probiotics act more efficiently in foods than in supplements? Nutrition 28:733

Rao D, Reddy A, Pulusani S, Cornwell P (1984) Biosynthesis and utilization of folic acid and vitamin $\mathrm{B}_{12}$ by lactic cultures in skim milk. J Dairy Sci 67:1169-1174

Ray J, Vermeulen M, Langman L, Boss S, Cole D (2003) Persistence of vitamin B12 insufficiency among elderly women after folic acid food fortification. Clin Biochem 36:387-391

Rossi M, Amaretti A, Raimondi S (2011) Folate production by probiotic bacteria. Nutrients 3:118-134

Sanders ME, Huis J (1999) Bringing a probiotic-containing functional food to the market: microbiological, product, regulatory and labeling issues. In: Lactic Acid Bacteria: Genetics, Metabolism and Applications. Springer, pp 293-315

Schrezenmeir J, de Vrese M (2001) Probiotics, prebiotics, and synbiotics - approaching a definition. Am J Clin Nutr 73:361s-364s

Sherwood KL, Houghton LA, Tarasuk V, O’Connor DL (2006) One-third of pregnant and lactating women may not be meeting their folate requirements from diet alone based on mandated levels of folic acid fortification. J Nutr 136:2820-2826 
Singh K, Kallali B, Kumar A, Thaker V (2011) Probiotics: a review. Asian Pac J Trop Biomed 1:S287-S290. doi:10.1016/S2221-1691(11)60174-3

Storozhenko S, Ravanel S, Zhang G-F, Rébeillé F, Lambert W, Van Der Straeten D (2005) Folate enhancement in staple crops by metabolic engineering. Trends Food Sci Technol 16:271-281

Sweeney MR, McPartlin J, Scott J (2007) Folic acid fortification and public health: report on threshold doses above which unmetabolised folic acid appear in serum. BMC Public Health 7:41

Sybesma WF (2003) Metabolic engineering of folate production in lactic acid bacteria. Thesis Wageningen University, Netherlands

Sybesma W, Starrenburg M, Tijsseling L, Hoefnagel MH, Hugenholtz J (2003) Effects of cultivation conditions on folate production by lactic acid bacteria. Appl Environ Microbiol 69:4542-4548

Ulrich CM, Potter JD (2006) Folate supplementation: too much of a good thing? Cancer Epidemiol Biomark Prev 15:189-193

Vahteristo L, Finglas P (2000) Chromatographic determination of folates. Chromatogr Sci Ser 84:301-324

Wright AJ, Dainty JR, Finglas PM (2007) Folic acid metabolism in human subjects revisited: potential implications for proposed mandatory folic acid fortification in the UK. Br J Nutr 98:667-675 